\title{
Effects of acetazolamide in patients with the sleep apnoea syndrome
}

\author{
HIROKAZU TOJIMA, FUMIO KUNITOMO, HIROSHI KIMURA, \\ KOICHIRO TATSUMI, TAKAYUKI KURIYAMA, YOSHIYUKI HONDA
}

From the Department of Chest Medicine, Institute of Pulmonary Cancer Research, and Department of Physiology, School of Medicine, Chiba University, Chiba, Japan

ABSTRACT There is as yet no convincing evidence that acetazolamide, a carbonic anhydrase inhibitor, is effective in obstructive sleep apnoea. A study was therefore designed to examine the effect of acetazolamide $(250 \mathrm{mg} /$ day $)$ on sleep events and ventilatory control during wakefulness in nine patients with the sleep apnoea syndrome. In eight of the nine patients the apnoea index and the total duration of apnoea were reduced by acetazolamide, and the mean (SEM) apnoea index of all patients changed from $25 \cdot 0(6 \cdot 7)$ to $18 \cdot 1(5 \cdot 8)$ episodes an hour. Furthermore, the total time of arterial oxygen desaturation $\left(\mathrm{SaO}_{2}\right)$-more than $4 \%$ depression in $\mathrm{SaO}_{2}$ from the baseline sleeping level-divided by total sleep time was also significantly decreased and its mean (SEM) value improved from $24 \cdot 1(7 \cdot 9)$ to $13.6(4.8) \%$ of total sleep time. Five of the seven patients with varying degrees of daytime hypersomnolence had their symptoms obviously improved. There was no patient whose predominant type of apnoea was converted from the obstructive to the central type, or vice versa. In the studies of wakefulness, metabolic acidosis, an increase of arterial oxygen tension $\left(\mathrm{PaO}_{2}\right)$ and a decrease of arterial carbon dioxide tension $\left(\mathrm{PaCO}_{2}\right)$ were observed. The slopes of the occlusion pressure response and the ventilatory response to carbon dioxide increased, and the carbon dioxide ventilatory response line shifted to the left. It is suggested that acetazolamide cannot remove apnoea completely but has a beneficial effect in mild cases of obstructive sleep apnoea through an augmentation of central $\left(\mathrm{CO}_{2}\right.$, $\mathrm{H}^{+}$) drive and a stabilising effect on ventilatory control.

Owing to insufficient knowledge about the pathogenesis of the sleep apnoea syndrome, effective treatment for most such patients has yet to be established. Current treatment is based merely on the physical findings of the patients, the type of apnoea, and the severity of the syndrome. Drugs such as protriptyline ${ }^{12}$ and medroxyprogesterone acetate ${ }^{34}$ for obstructive and central sleep apnoea were reported to be effective in only a few patients.

Acetazolamide induces metabolic acidosis by inhibiting carbonic anhydrase in the renal tubular structures and stimulates ventilation. Furthermore, it may increase cerebral carbon dioxide tension $\left(\mathrm{PCO}_{2}\right)$ by impeding carbon dioxide transport and may suppress formation of cerebrospinal fluid bicarbonate at the same time, resulting in a sustained increase in alveolar ventilation.

Address for reprint requests: Dr H Tojima, Department of Chest Medicine, Institute of Pulmonary Cancer Research, School of Medicine, Chiba University, Chiba 280, Japan.

Accepted 13 October 1987
This agent has been used successfully to improve periodic breathing during sleep at high altitude,${ }^{56}$ and was also reported to be useful in central sleep apnoea. ${ }^{7}$ On the other hand, Sharp et $a l^{8}$ observed that acetazolamide induced metabolic acidosis converted central to obstructive apnoea and worsened hypoxaemia in two patients with mixed apnoea. Shore et al ${ }^{9}$ reported a similar case. It remains to be determined therefore whether acetazolamide is useful or not for the treatment of sleep apnoea syndrome, and particularly for the subgroup with obstructive disease.

In the present investigation we have assessed the effect of acetazolamide in patients with sleep apnoea syndrome on indices of sleep disorder and ventilatory control during wakefulness.

\section{Methods}

Five men and four women patients with sleep apnoea syndrome were studied (table 1). In most of them polysomnography was performed because of their symptoms-for example, heavy snoring, excessive 
Table 1 Anthropometric and pulmonary function data of the patients with sleep apnoea syndrome

\begin{tabular}{|c|c|c|c|c|c|c|c|c|c|c|}
\hline & \multirow[b]{2}{*}{ Age, sex } & \multirow[b]{2}{*}{$\begin{array}{l}\text { Height } \\
(\mathrm{cm})\end{array}$} & \multirow[b]{2}{*}{$\begin{array}{l}\text { Weight } \\
(\mathrm{kg})\end{array}$} & \multirow[b]{2}{*}{$\begin{array}{l}\text { Weight } \\
\text { (\% of ideal) }\end{array}$} & \multicolumn{4}{|c|}{ Resting arterial blood gas } & \multirow[b]{2}{*}{$\begin{array}{l}V C \\
\text { (\% pred) }\end{array}$} & \multirow[b]{2}{*}{$F E V_{1} \%$} \\
\hline & & & & & $p H$ & $\begin{array}{l}\mathrm{Paco}_{2} \\
(\mathrm{kPa})\end{array}$ & $\begin{array}{l}\mathrm{PaO}_{2} \\
(\mathrm{kPa})\end{array}$ & $\begin{array}{l}{\left[\mathrm{HCO}_{3}^{-}\right]{ }_{(\mathrm{mmol} / 1)}}\end{array}$ & & \\
\hline $\begin{array}{l}1 \\
2 \\
3 \\
4 \\
5 \\
6 \\
7 \\
8 \\
9 \\
\text { Mean } \\
\text { SEM }\end{array}$ & $\begin{array}{l}62, \mathrm{~F} \\
33, \mathrm{M} \\
58, \mathrm{~F} \\
65, \mathrm{M} \\
47, \mathrm{M} \\
72, \mathrm{~F} \\
72, \mathrm{~F} \\
53, \mathrm{M} \\
61, \mathrm{M} \\
58 \\
4\end{array}$ & $\begin{array}{r}147 \\
162 \\
147 \\
172 \\
163 \\
159 \\
144 \\
167 \\
163 \\
158 \\
3\end{array}$ & $\begin{array}{l}76 \\
90 \\
85 \\
76 \\
76 \\
65 \\
36 \\
92 \\
78 \\
75 \\
6\end{array}$ & $\begin{array}{r}153 \\
150 \\
171 \\
113 \\
134 \\
123 \\
74 \\
153 \\
138 \\
134 \\
10\end{array}$ & $\begin{array}{l}7 \cdot 40 \\
7 \cdot 40 \\
7 \cdot 35 \\
7 \cdot 38 \\
7 \cdot 40 \\
7 \cdot 42 \\
7 \cdot 41 \\
7 \cdot 35 \\
7 \cdot 40 \\
7 \cdot 39 \\
0 \cdot 01\end{array}$ & $\begin{array}{l}6 \cdot 3 \\
5 \cdot 0 \\
6 \cdot 9 \\
5 \cdot 9 \\
5 \cdot 2 \\
5 \cdot 9 \\
5 \cdot 3 \\
5 \cdot 9 \\
5 \cdot 3 \\
5 \cdot 7 \\
0 \cdot 2\end{array}$ & $\begin{array}{r}7.5 \\
10.5 \\
7.8 \\
10.4 \\
8.8 \\
9.0 \\
11.4 \\
10.0 \\
10.2 \\
9.5 \\
0.4\end{array}$ & $\begin{array}{r}28 \cdot 8 \\
23 \cdot 4 \\
27 \cdot 9 \\
25 \cdot 7 \\
24 \cdot 7 \\
28 \cdot 5 \\
25 \cdot 2 \\
25 \cdot 0 \\
24 \cdot 7 \\
26 \cdot 0 \\
0.6\end{array}$ & $\begin{array}{r}69 \\
109 \\
70 \\
71 \\
97 \\
81 \\
72 \\
81 \\
88 \\
82 \\
5\end{array}$ & $\begin{array}{l}49 \\
85 \\
70 \\
42 \\
70 \\
70 \\
60 \\
79 \\
84 \\
68 \\
5\end{array}$ \\
\hline
\end{tabular}

Conversion: SI to traditional units-Blood gas data: $1 \mathrm{kPa}=7.5 \mathrm{~mm} \mathrm{Hg}$.

daytime sleepiness, and insomniac sensation. The predominant apnoea was the obstructive type, which was present in eight obese patients; one patient (case 7) who had purely central apnoea accompanied by Cheyne-Stokes respiration was not obese. Patients 1 and 3 were mildly hypercapnic, and patients 1 and 4 had chronic obstructive pulmonary disease. Some of the patients were being treated with several drugs that continued to be administered throughout the study. At the time of the study all subjects were clinically stable.

Before administering acetazolamide we performed polysomnography for two consecutive nights, studies of ventilatory control during wakefulness, pulmonary function tests, and arterial blood gas analysis. In the acetazolamide treatment run, $250 \mathrm{mg}$ was given orally once a day and the tests were repeated on the seventh or eighth day of administration.

During the sleep studies surface electrodes were applied to obtain an electroencephalogram (EEG), an electrooculogram (EOG) and a submental electromyogram [EMG). Arterial oxygen saturation $\left(\mathrm{SaO}_{2}\right)$ was measured continuously with an ear oximeter (Biox IIA). Movement of the chest wall and abdomen was measured with an inductance plethysmograph (Respitrace) and nasal flow with a thermistor. A polygraph was used to record all the variables.

Sleep stages were determined by the criteria of Rechtschaffen and Kales. ${ }^{10}$ Apnoea was defined as cessation of flow at the nose for at least 10 seconds. Central apnoea was thought to occur when respiratory effort and airflow were absent, and obstructive apnoea when respiratory effort continued without airflow. Hypopnoea was defined when airflow and respiratory movement were reduced in amplitude by one third, with a depression in $\mathrm{SaO}_{2}$."

Resting ventilatory indices, inspiratory minute ventilation $\left(\mathrm{V}_{\mathrm{I}}\right)$, tidal volume (VT), respiratory frequency (f), mean inspiratory flow ( $\mathrm{VT} / \mathrm{TI})$ and duty cycle (TI/ TT) were determined in seven patients while they were breathing through a mouthpiece. VT, inspiratory $\vec{T}$ duration $(\mathrm{TI})$, and expiratory duration $(\mathrm{TE})$ were 을 electrically displayed by an analogue calculator from the flow signal detected with a hot wire flow meter (Minato RF-H).

Hypoxic and hypercapnic ventilatory responses $\infty_{\infty}^{\infty}$ during wakefulness were measured in seven and eight patients respectively. Hypoxic ventilatory response was determined by an isocapnic progressive hypoxia test. During acetazolamide administration, as the end tidal $\mathrm{PCO}_{2}\left(\mathrm{PET} \mathrm{CO}_{2}\right)$ decreased owing to drug induced $\frac{\circ}{\Phi}$ hyperventilation, measurement of the hypoxic ventilatory response was made at a PET $\mathrm{CO}_{2}$ lower than the pretreatment level. The hypoxic ventilatory response was evaluated from the linear regression between $\dot{\mathrm{V}}$ and $\mathrm{SaO}_{2}$ as well as between mouth occlusion pressure at 0.2 seconds $(\mathrm{P} 0 \cdot 2)^{12}$ and $\mathrm{SaO}_{2}$, and their response slopes were termed as $\Delta \mathrm{V} / / \Delta \mathrm{SaO}_{2}$ and $\Delta \mathrm{P} 0 \cdot 2 / \Delta \mathrm{SaO}_{2} \stackrel{\mathrm{O}}{\mathrm{O}}$ respectively. The hypercapnic ventilatory response ${ }_{\sigma}^{x}$ was measured by Read's rebreathing method, and was 3 . evaluated by the slopes of linear regression between $\mathrm{V} i \dot{\rho}$ and $\mathrm{PET} \mathrm{CO}_{2}$ as well as between $\mathrm{P0} \cdot 2$ and $\operatorname{PET~} \mathrm{CO}_{2}\left(\Delta \dot{\mathrm{V}}_{\mathrm{I}} / \overline{\mathrm{O}}\right.$ $\Delta \mathrm{PCO}_{2}$ and $\Delta \mathrm{P} 0 \cdot 2 / \Delta \mathrm{PCO}_{2}$ respectively). Details about the sleep study and the ventilatory response test have been reported previously. ${ }^{1314}$

Statistical analysis was performed by paired $t$ test after confirmation that the variability within each o group was the same.

\section{Results}

SYMPTOMS AND SIDE EFFECTS

Five of the seven patients who had varying degrees of? daytime sleepiness, the four who felt difficulty in achieving full arousal on awakening, and three of the four who had an insomniac sensation had their吕 symptoms improved to some degree during acetazolamide administration. Though two patients $\Omega$ complained of dysaesthesia of the extremities and 
Table 2 Effects of acetazolamide on arterial blood gases, resting ventilation, and hypoxic amd hypercapnic ventilatory responses (mean (SEM) values)

\begin{tabular}{|c|c|c|c|c|c|c|}
\hline \multirow[b]{2}{*}{$\begin{array}{l}\mathrm{pH} \\
\mathrm{PaCO}_{2}(\mathrm{kPa}) \\
\mathrm{PaO}_{2}(\mathrm{kPa}) \\
{\left[\mathrm{HCO}_{3}^{-}\right](\mathrm{mmol} / \mathrm{l})} \\
\mathrm{VI}\left(1 \mathrm{~min}^{-1}\right) \\
\mathrm{VT}(1) \\
\mathrm{f} \\
\mathrm{VT} / \mathrm{TI}\left(1 \mathrm{~s}^{-1}\right) \\
\mathrm{TI} / \mathrm{TT} \\
\Delta \mathrm{P} 0 \cdot 2 / \Delta \mathrm{SaO}_{2}\left(\mathrm{kPa}^{-1} \%^{-1}\right) \\
\Delta \dot{V}_{\mathrm{I}} / \Delta \mathrm{SaO}_{2}\left(1 \mathrm{~min}^{-1} \%^{-1}\right) \\
\Delta \dot{\mathrm{V}}_{\mathrm{I}} \mathrm{at} \mathrm{SaO}_{2} 75 \%\left(1 \mathrm{~min}^{-1}\right) \\
\Delta \mathrm{P} 0 \cdot 2 / \Delta \mathrm{PCO}_{2} \\
\Delta \dot{\mathrm{V}}_{\mathrm{I}} / \Delta \mathrm{PCO}_{2}\left(1 \mathrm{~min}^{-1} \mathrm{kPa}^{-1}\right) \\
\hat{\mathrm{V}}_{\mathrm{I}} \text { at } \mathrm{PCO}_{2} 8 \cdot 0 \mathrm{kPa}^{-1}\left(1 \mathrm{~min}^{-1}\right)\end{array}$} & $\frac{n}{9}$ & \multicolumn{2}{|l|}{ Control } & \multicolumn{2}{|c|}{ Acetazolamide } & $\frac{p}{<0.001}$ \\
\hline & $\begin{array}{l}9 \\
9 \\
9 \\
9 \\
7 \\
7 \\
7 \\
7 \\
7 \\
7 \\
7 \\
7 \\
8 \\
8 \\
8\end{array}$ & $\begin{array}{c}7.39 \\
5 \cdot 7 \\
9.5 \\
26.0 \\
9.0 \\
0.55 \\
17.6 \\
0.38 \\
0.39 \\
-0.024 \\
-0.50 \\
19.4 \\
0.76 \\
9.2 \\
21.6\end{array}$ & $\begin{array}{l}(0 \cdot 01) \\
(0 \cdot 2) \\
(0 \cdot 4) \\
(0 \cdot 6) \\
(1 \cdot 0) \\
(0 \cdot 09) \\
(1 \cdot 7) \\
(0.03) \\
(0.02) \\
(0.007) \\
(0 \cdot 17) \\
(3 \cdot 3) \\
(0 \cdot 11) \\
(1 \cdot 3) \\
(3 \cdot 9)\end{array}$ & $\begin{array}{c}7.34 \\
4.8 \\
11.1 \\
19.6 \\
10.8 \\
0.58 \\
19.9 \\
0.44 \\
0.40 \\
-0.032 \\
-0.38 \\
17.5 \\
1.05 \\
14.2 \\
35.6\end{array}$ & $\begin{array}{l}(0 \cdot 01) \\
(0.5) \\
(1 \cdot 1) \\
(0 \cdot 6) \\
(1 \cdot 2) \\
(0.08) \\
(2 \cdot 8) \\
(0.05) \\
(0.03) \\
(0.013) \\
(0 \cdot 10) \\
(2 \cdot 6) \\
(0 \cdot 12) \\
(2 \cdot 5) \\
(5 \cdot 5)\end{array}$ & $\begin{array}{l}<0.001 \\
<0.001 \\
<0.001 \\
<0.001 \\
<0.1 \\
\text { NS } \\
\text { NS } \\
\text { NS } \\
\text { NS } \\
\text { NS } \\
\text { NS } \\
\text { NS } \\
<0.001 \\
<0.05 \\
<0.01\end{array}$ \\
\hline
\end{tabular}

Conversion: SI to traditional units-Blood gas data: $1 \mathrm{kPa}=7 \cdot 5 \mathrm{~mm} \mathrm{Hg}$; occlusion pressure (P0.2) data: $1 \mathrm{kPa}=10 \cdot 2 \mathrm{~cm} \mathrm{H}_{2} \mathrm{O}$.

another complained of pollakiuria, all patients able to continue taking the drug.

\section{AWAKE RESPONSE}

The effects of acetazolamide on arterial blood gas tensions, resting ventilatory indices, and the ventilatory response to hypoxia and hypercapnia during wakefulness are shown in table 2 . The acetazolamide treatment produced metabolic acidosis, as shown by the decrease in $\left[\mathrm{HCO}_{3}^{-}\right]$and $\mathrm{pH} . \mathrm{PaCO}_{2}$ decreased by a mean of $0.9 \mathrm{kPa}(6.8 \mathrm{~mm} \mathrm{Hg})$ and $\mathrm{PaO}_{2}$ increased by a mean of $1.6 \mathrm{kPa}(12.0 \mathrm{~mm} \mathrm{Hg})$. The mean values of $\dot{\mathrm{V}}_{\mathrm{I}}$, $\mathrm{VT}$, and $\mathrm{f}$ during wakefulness increased but their changes were not significant. There was no significant change in the hypoxic responses expressed as $\Delta \mathrm{P} 0 \cdot 2 /$ $\Delta \mathrm{SaO}_{2}$ and $\Delta \dot{\mathrm{V}}_{\mathrm{I}} / \Delta \mathrm{SaO}_{2}$. On the other hand, in the carbon dioxide response study the slopes of the occlusion pressure response $\left(\Delta \mathrm{P} 0 \cdot 2 / \Delta \mathrm{PCO}_{2}\right)$ and the ventilatory response $\left(\Delta \dot{\mathrm{V}}_{\mathrm{I}} / \Delta \mathrm{PCO}_{2}\right)$ increased significantly. Furthermore, the mean value of $\dot{V}_{I}$ at PET $\mathrm{CO}_{2}$ $8.0 \mathrm{kPa}(60 \mathrm{~mm} \mathrm{Hg})$ increased significantly, thereby indicating that the position of the carbon dioxide ventilatory response line shifted to a lower $\mathrm{PCO}_{2}$ range.

\section{SLEEP RESPONSE}

The total sleep time, sleep efficiency (total sleep time divided by total time in bed), and sleep stage distribution were not altered during acetazolamide treatment (table 3). Before acetazolamide administration the apnoea index (number of episodes/hour of total sleep time) of the nine patients varied from 5.4 to $57 \cdot 1$, with a mean of $25 \cdot 0$ (fig 1). The two patients with an apnoea index below 10 had loud snoring and daytime hypersomnolence. With acetazolamide treatment the mean value of the apnoea index was reduced to $18 \cdot 1$ (range $0 \cdot 8-43 \cdot 5)$. This reduction was significant. Furthermore, the total apnoea time divided by total sleep time also diminished significantly. On the other hand, the number of hypopnoeic episodes per unit sleep time did not change significantly. The mean number of arousals per hour seen on the EEG fell from 7.4 to 4.5.

To assess sleep disturbance, we used the changes of maximal oxygen desaturation during non-REM and REM sleep and the total time of desaturation (more

Table 3 Effects of acetazolamide on sleep events in nine subjects (mean (SEM) values)

\begin{tabular}{|c|c|c|c|c|c|}
\hline \multirow[b]{2}{*}{$\begin{array}{l}\text { Total sleep time (TST) (h) } \\
\text { Sleep efficiency (TST/time in bed) } \\
\text { Sleep stage (\%) I } \\
\text { II } \\
\text { SWS } \\
\text { REM } \\
\text { Apnoea index (episodes/hour of TST) } \\
\text { Hypopnoea index (episodes/hour of TST) } \\
\text { Total apnoea time/TST (\%) } \\
\text { Oxygen saturation (\%) }\end{array}$} & \multicolumn{2}{|c|}{ Control } & \multicolumn{2}{|c|}{ Acetazolamide } & \multirow[b]{2}{*}{$\begin{array}{l}p \\
\text { NS } \\
\text { NS } \\
\text { NS } \\
\text { NS } \\
\text { NS } \\
\text { NS } \\
<0.02 \\
\text { NS } \\
<0.05\end{array}$} \\
\hline & $\begin{array}{c}6 \cdot 8 \\
0 \cdot 79 \\
20 \\
47 \\
12 \\
21 \\
25 \cdot 0 \\
7 \cdot 3 \\
23 \cdot 0\end{array}$ & $\begin{array}{l}(0 \cdot 5) \\
(0 \cdot 06) \\
(2) \\
(5) \\
(2) \\
(3) \\
(6 \cdot 7) \\
(2 \cdot 6) \\
(7 \cdot 0)\end{array}$ & $\begin{array}{l}6 \cdot 9 \\
0 \cdot 81 \\
19 \\
49 \\
12 \\
20 \\
18 \cdot 1 \\
5 \cdot 7 \\
15 \cdot 3\end{array}$ & $\begin{array}{l}(0 \cdot 5) \\
(0 \cdot 05) \\
(2) \\
(4) \\
(1) \\
(3) \\
(5 \cdot 8) \\
(2 \cdot 3) \\
(4 \cdot 9)\end{array}$ & \\
\hline $\begin{array}{l}\text { Baseline } \\
\text { Nadir (non-REM) } \\
\text { Nadir (REM) } \\
\text { Desaturation time }(>4 \%) / \text { TST }(\%)\end{array}$ & $\begin{array}{l}93 \\
77 \\
71 \\
24 \cdot 1\end{array}$ & $\begin{array}{l}(1) \\
(4) \\
(5) \\
(7 \cdot 9)\end{array}$ & $\begin{array}{l}94 \\
81 \\
73 \\
13 \cdot 6\end{array}$ & $\begin{array}{l}(1) \\
(3) \\
(5) \\
(4 \cdot 8)\end{array}$ & $\begin{array}{l}\text { NS } \\
<0.05 \\
\text { NS } \\
<0.02\end{array}$ \\
\hline
\end{tabular}

Values are means (SEM). $\mathbf{n}=9$.

SWS-slow wave sleep; REM-rapid eye movement sleep. 


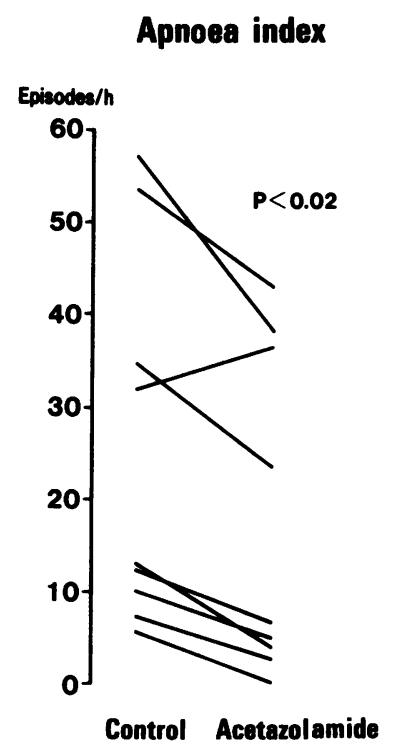

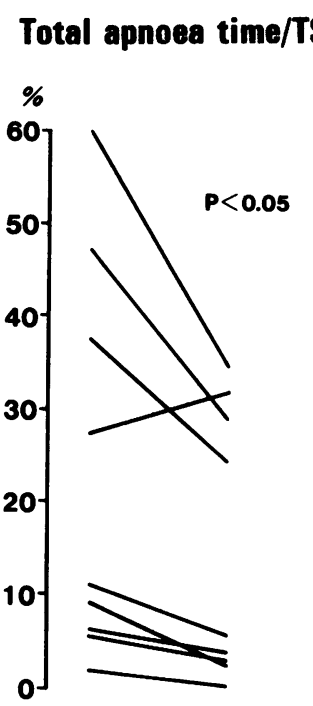

Control Acetazolamide

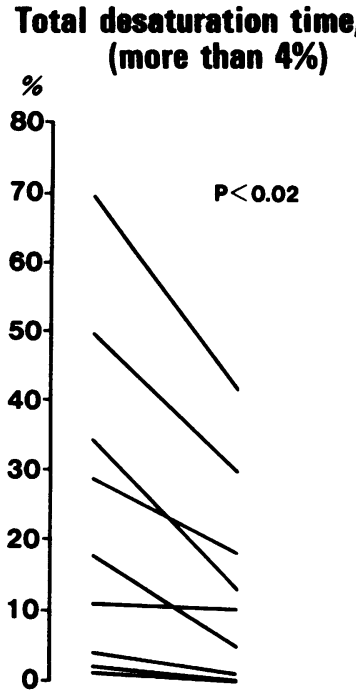

Control Acotazolamide

Fig 1 Changes of sleep events in the nine patients with the sleep apnoea syndrome: comparison of control and values during acetazolamide (250 mg/day) treatment. TST-total sleep time.

than $4 \%$ depression in $\mathrm{SaO}_{2}$ from the baseline sleeping level) divided by total sleep time. The baseline and the lowest $\mathrm{SaO}_{2}$ in REM sleep showed a tendency to increase, but these changes were not significant. The lowest $\mathrm{SaO}_{2}$ in non-REM sleep, however, increased significantly. Furthermore, the percentage of total desaturation time decreased significantly. This value in the nine patients had varied from $1.0 \%$ to $69.2 \%$ (mean $24.1 \%$ ) during the control period, and the improved values were $0 \cdot 1-42 \cdot 1 \%$ (mean $13.6 \%$ ) during acetazolamide administration. The apnoea index and apnoea time became worse in case 8 . This patient, however, had a diminished desaturation time owing to a considerable reduction in hypopnoeic episodes. On the other hand, in case 6, although the apnoea index decreased, the desaturation time did not change owing to the increase in episodes of hypopnoea. This patient showed a fluttering pattern in the expiratory limb of the flow-volume loop that may have reflected the upper airway obstruction he had while awake. ${ }^{15}$

Disordered breathing was most likely to occur in sleep stages 1 and 2 and in REM sleep, except in the patient who had Cheyne-Stokes respiration with periodic apnoea, which considerably decreased during REM sleep. When the effect of acetazolamide in REM sleep and in non-REM sleep was compared, a significant decrease of the apnoea index was observed in each stage (fig 2).

The patients had predominantly obstructive apnoea except for the patient with Cheyne-Stokes respiration,

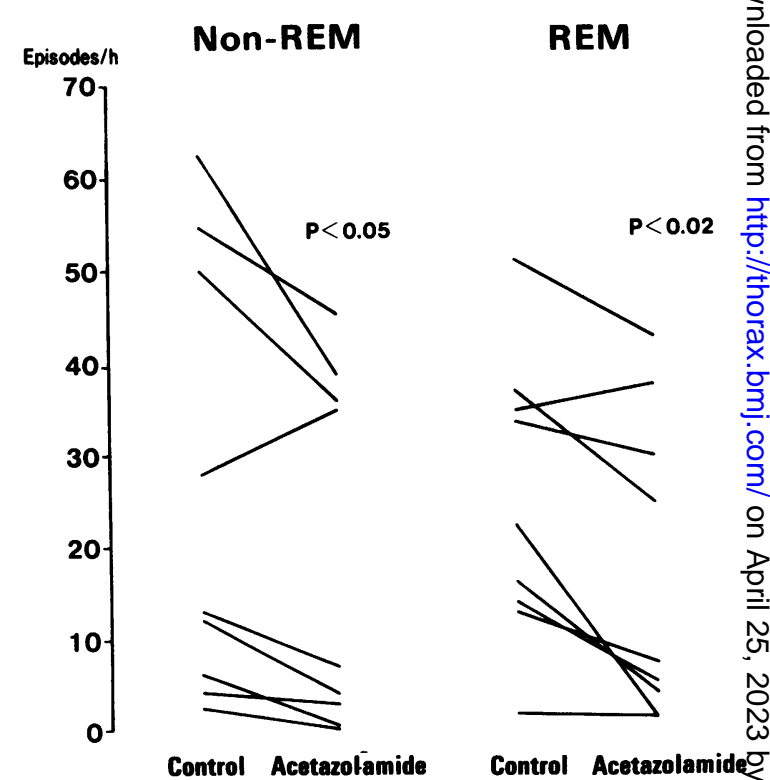

Fig 2 Changes in apnoea index (number of apnoeic episodes $\stackrel{0}{\frac{C}{C}}$ per hour of total sleep time) during non-REM and REM 足 sleep associated with acetazolamide treatment.

but central and mixed types of apnoea were also $\frac{\Omega}{\mathbb{D}}$ observed to some extent. In no case was the type of apnoea that predominated induced by acetazolamide. 
The changes in the apnoea index, total apnoea time/ total sleep time, and desaturation time/total sleep time were not significantly related to changes in the ventilatory and occlusion pressure responses to carbon dioxide during wakefulness. Moreover, they were not correlated with changes in $\mathrm{PaCO}_{2}$ and $\mathrm{PaO}_{2}$

\section{Discussion}

We found in this study that acetazolamide reduced but did not remove the episodes of obstructive apnoea and oxygen desaturation during sleep and that it ameliorated clinical symptoms associated with disordered breathing. Acetazolamide has been shown to be effective in two sorts of sleep disordered breathing. Firstly, during acute high altitude exposure acetazolamide was reported to reduce the number of episodes of periodic breathing and improve arterial oxygen saturation. ${ }^{56}$ Acetazolamide is known to be useful for the prevention of acute mountain sickness. ${ }^{16}$ Secondly, White and colleagues ${ }^{7}$ reported that acetazolamide substantially reduced episodes of central apnoea in all their six patients. Findley et al $^{17}$ noted that acetazolamide calmed down the oscillations of ventilatory movement and abolished the recurrent episodes of apnoea in Cheyne-Stokes breathing. In contrast, Sharp and colleagues ${ }^{8}$ showed that metabolic acidosis produced by acetazolamide converted central apnoea to obstructive or mixed apnoea. The reason for this remains uncertain, but it may very well be due to the generation of greater negative inspiratory pressure, facilitating upper airway closure. No further reports, however, have appeared to substantiate the evidence of either beneficial or adverse effects of acetazolamide on obstructive sleep apnoea.

The number of apnoeic episodes per hour of total sleep time during the control period varied from 5.4 to 57.1; in two mild cases it was less than 10. The conventional definition for sleep apnoea syndromemore than five apnoeic episodes an hour-may in fact be an inappropriately small index number for predicting increased health risk or somnolence in subjects over 60 years of age. ${ }^{18}$ The two patients with the mild syndrome, however, were a 33 year old man and a 58 year old woman. We therefore diagnosed them as having sleep apnoea syndrome. The mean apnoea index of our subjects was $25 \cdot 0$, indicating a relatively mild sleep apnoea syndrome. The one patient with severe obstructive apnoea treated with acetazolamide but failing to show improvement in oxygen desaturation had the so called "saw tooth" configuration in her expiratory flow-volume curve. ${ }^{19}$ In cases where obstructing lesion or abnormality is present in the upper airway it may be difficult to improve the disordered breathing.
In our study one patient who had purely central apnoea did not develop obstructive apnoea with acetazolamide treatment. Önal and colleagues ${ }^{20}$ found that occlusive and mixed apnoeic episodes occurred at the nadir of periodic fluctuation in diaphragmatic and genioglossal activities, suggesting that both types of apnoea resulted from an instability of ventilatory control during sleep. Their recent report ${ }^{21}$ showed that occlusive sleep apnoea resulted from hypoxia induced periodic breathing in the presence of inspiratory resistive loading in normal volunteers. Remmers and colleagues ${ }^{22}$ having studied patients with the Pickwickian syndrome, indicated that the genioglossal electromyogram fluctuated systematically in relation to the periodic breathing cycle: low level activity at the onset of occlusion and prominent discharge at the instant of pharyngeal opening. From these investigations it is suggested that the pathogenesis of obstructive apnoea is related to the instability of ventilatory control in the presence of structural encroachment in the oropharyngeal lumen. Thus administration of an agent capable of producing a stabilising effect on respiratory control may be useful for patients with obstructive sleep apnoea, unless the patient has an obstructive lesion in the upper airway.

In the present study distinctive findings were metabolic acidosis and an augmentation of hypercapnic chemosensitivity during wakefulness after acetazolamide administration. Furthermore, we observed augmentation of minute ventilation at a $\mathrm{PCO}_{2}$ of $8.0 \mathrm{kPa}(60 \mathrm{~mm} \mathrm{Hg})$, which indicated left hand shift in the hypercapnic ventilatory response line. We previously confirmed that metabolic acidosis produced by acetazolamide increased ventilation and chemosensitivity to carbon dioxide in healthy men. ${ }^{23}$ In this previous study, however, the augmentation of the ventilatory response to carbon dioxide by acetazolamide was larger than that by ammonium chloride induced acidosis and therefore the effect of impeding carbon dioxide transport with a resultant increase in cerebral $\mathrm{PCO}_{2}$ and $\left[\mathrm{H}^{+}\right]$might affect carbon dioxide chemosensitivity. If acetazolamide preserved ventilatory stability during sleep and functioned to reduce periodic apnoea, the following factors that may account for improving sleep disorders can be considered. Firstly, a left hand shift of the carbon dioxide response line reduces the tendency for periodic breathing owing to a stabilising effect. ${ }^{24}$ Secondly, the enhanced ventilation induced by metabolic acidosis reduces hypoxia, and the augmented central $\left(\mathrm{CO}_{2}, \mathrm{H}^{+}\right)$ drive and the relief of hypoxia decrease the relative influence of the hypoxic drive that makes the ventilatory control more unstable than the $\left(\mathrm{CO}_{2}, \mathrm{H}^{+}\right)$ driving system. Several studies suggest that oxygen administration may favourably influence central sleep apnoea. ${ }^{25}$ 
During acetazolamide treatment comparison of the hypoxic ventilatory response with the control response was difficult because $\mathrm{PCO}_{2}$ was depressed by the drug administration. Whether there is an interactive effect between metabolic acidosis and hypoxic chemosensitivity remains to be determined, ${ }^{26}{ }^{27}$ but our previous study $^{23}$ and that of Powles $e t a l^{8}$ indicated that acetazolamide did not enhance the hypoxic ventilatory response in eucapnic conditions. Another possible mechanism for reducing episodes of apnoea by acetazolamide is alteration of the distribution profile of sleep stages, as was seen after protriptyline. ${ }^{2}$ In our results, however, there was no remarkable change in sleep stages, and acetazolamide reduced sleep apnoea similarly in both non-REM and REM sleep, except in one patient, whose apnoea index increased only in non-REM sleep. A significant increase in lowest $\mathrm{SaO}_{2}$ was seen in non-REM sleep, whereas a significant improvement in apnoea index was observed in each sleep stage. From these findings it is difficult to believe that acetazolamide had different effects on non-REM and on REM sleep.

To evaluate the effect of a chemical agent on sleep disordered breathing in patients with sleep apnoea syndrome, quantitative measurement appears to be as important for hypopnoeic episodes as for apnoea. In fact, in our study there was one patient whose apnoeic episodes were diminished but hypopnoeic episodes were increased, so that the total desaturation time was not improved. Oxygen desaturation time depends on lung volume (functional residual capacity), baseline $\mathrm{SaO}_{2}$, and the number and duration of episodes of apnoea and hypopnoea. Thus the beneficial effects of acetazolamide on sleep apnoea syndrome seem to be reflected by the reduction of desaturation time.

On the other hand, care must be taken regarding the negative effects of acetazolamide. Since it is known that metabolic acidosis affects pulmonary arterial resistance, cardiac contractility, and oxygen transport, this drug should be used only in conjunction with careful control of arterial $\mathrm{pH}$. We used only $250 \mathrm{mg}$ of acetazolamide a day to avoid the development of severe metabolic acidosis. Since mean arterial pH decreased from 7.39 to 7.34 with this dose, the administration of more than $250 \mathrm{mg}$ per day would appear to be unwise. If the depression of bicarbonate concentration develops without concomitant lowering of $\mathrm{PaCO}_{2}$, the resulting severe metabolic acidosis may endanger some vital organs, and might finally become life threatening. ${ }^{29} 30$

We thank Drs S Okita, Y Yuguchi, S Masuyama, S Kouchiyama, T Shinozaki, S Tazawa, and T Miyagi for cooperation and valuable discussion. This work was supported in part by a grant from the research committee for intractable respiratory failure of the Ministry of Health and Welfare of Japan.

\section{References}

1 Clark RW, Schmidt HS, Schaal SF, Boudoulas H, $\frac{\bar{\sigma}}{\bar{\omega}}$ Schuller DE. Sleep apnea: treatment with protriptyline. $\stackrel{\vec{D}}{\vec{D}}$ Neurology 1979;29:1287-92.

2 Brownell LG, West P, Sweatman P, Acres JC, @ Kryger MH. Protriptyline in obstructive sleep apnea. A $\vec{\circ}$ double-blind trial. $N$ Engl J Med 1982;307:1037-42.

3 Sutton FD, Zwillich CW, Creagh CE, Pierson DJ, $\overrightarrow{\vec{\omega}}$ Weil JV. Progesterone for outpatient treatment of $\widehat{\omega}$ Pickwickian syndrome. Ann Intern Med 1975;83:476-9.

4 Strohl KP, Hensley MJ, Saunders NA, Scharf SM, Brown R, Ingram RH. Progesterone administration $\vec{\omega}$ and progressive sleep apneas. JAMA 1981;245:1230-2. N

5 Weil JV, Kryger MH, Scoggin CH. Sleep and breathing at $\overrightarrow{\vec{\omega}}$ high altitude. In: Guilleminault C, Dement WC, eds. $\omega$ Sleep apnea syndrome. New York: Alan R Liss, 은 1978:119-36.

6 Sutton JR, Gray GW, Houston CS, Powles ACP. Effects T⿱ of duration at altitude and acetazolamide on ventila- 을 tion and oxygenation during sleep. Sleep 1980;3: 455-64.

7 White DP, Zwillich CW, Pickett CK, Douglas NJ, $\vec{C}$ Findley LJ, Weil JV. Central sleep apnea. Improvement with acetazolamide therapy. Arch Intern Med ${ }^{\infty}$ 1982;142:1816.

8 Sharp JT, Druz WS, D'Souza V, Diamond E. Effect of metabolic acidosis upon sleep apnea. Chest 1985;87: $\frac{\partial}{\partial}$ 619-24.

9 Shore ET, Millman RP. Central sleep apnea and aceta- $\frac{\circ}{\mathbb{D}}$ zolamide therapy. Arch Intern Med 1983;143:1278-80. 을

10 Rechtaschaffen A, Kales A, eds. A manual of standardized $\overrightarrow{\bar{B}}$ terminology, techniques and scoring system for sleep stages of human subjects. Bethesda, Maryland: National Institutes of Health, 1968. (NIH publication No 2041.)

11 Wynne JW, Block AJ, Hemenway J, Hunt LA, Flick MR. Disordered breathing and oxygen desaturation during sleep in patients with chronic obstructive lung disease $\bar{\sigma}$ (COLD). Am J Med 1979;66:573-9.

12. Yoshida A, Hayashi F, Sasaki K, Masuda Y, Honda Y. Analysis of pressure profile in the occluded airway obtained at the beginning of inspiration in steady state hypercapnia. Am Rev Respir Dis 1981;124:252-6.

13 Tatsumi K, Kimura H, Kunitomo F, et al. Effect of $D$ chlormadinone acetate on ventilatory control in 을. patients with chronic obstructive pulmonary disease. $N$ Am Rev Respir Dis 1986;133:552-7.

14 Tatsumi K, Kimura H, Kunitomo F, Kuriyama T, N Watanabe S, Honda $Y$. Sleep arterial oxygen $N$ desaturation and chemical control of breathing during ${ }_{\sigma}^{\omega}$ wakefulness in COPD. Chest 1986;89:68-73.

15 Tammelin BR, Wilson AF, Borowiecki BDB, Sassin JF. Flow-volume curves reflect pharyngeal airway abnor- $\mathbb{D}$ malities in sleep apea syndrome. Am Rev Respir Dis $\stackrel{?}{?}$ 1983;128:712-5.

16 Forwand SA, Landowne M, Follansbee MJN, Hansen CJE. Effect of acetazolamide on acute mountain sickness. N Engl J Med 1968;279:839-45.

17 Findley LJ, Blackburn MR, Goldberger AL, Mandell A. Apneas and oscillation of cardiac ectopy in CheyneStokes breathing during sleep. Am Rev Respir Dis 0 1984;130:937-9. 
18 Berry DTR, Webb WB, Block AJ. Sleep apnea syndrome. A critical review of the apnea index as a diagnostic criterion. Chest 1984;86:529-31.

19 Haponik EF, Smith PL, Kaplan J, Bleecker ER. Flow-volume curves and sleep-disordered breathing: therapeutic implications. Thorax 1983;38:609-15.

20 Önal E, Lopata M, O'Connor M. Pathogenesis of apneas in hypersomnia-sleep apnea syndrome. Am Rev Respir Dis 1982;125:167-74.

21 Önal E, Burrows DL, Hart RH, Lopata M. Induction of periodic breathing during sleep causes upper airway obstruction in humans. J Appl Physiol 1986;61: 1438-43.

22 Remmers JE, deGroot WJ, Sauerland EK, Anch AM. Pathogenesis of upper airway occlusion during sleep. J Appl Physiol 1978;44:931-8.

23 Tojima H, Kunitomo F, Okita S, et al. Difference in the effects of acetazolamide and ammonium chloride acidosis on ventilatory responses to $\mathrm{CO}_{2}$ and hypoxia in humans. Jpn J Physiol 1986;36:511-21.

24 Cherniack NS, von Euler C, Homma I, Kao FF. Experimentally induced Cheyne-Stokes breathing. Respir Physiol 1979;37:185-200.
25 Martin RJ, Saunders MH, Gray BA, Pennock BE. Acute and long-term ventilatory effects of hyperoxia in the adult sleep apnea syndrome. Am Rev Respir Dis 1982;125:175-80.

26 Irsigler GB, Stafford MJ, Severinghaus JW. Relationship of CSF pH, $\mathrm{O}_{2}, \mathrm{CO}_{2}$ responses in metabolic acidosis and alkalosis in humans. J Appl Physiol 1980;48: 355-61.

27 Knill RL, Clement JL. Ventilatory responses to acute metabolic acidemia in humans awake, sedated, and anesthetized with halothane. Anesthesiology 1985;62: 745-53.

28 Powles ACP, Sutton JR, Rigg JRA. Acetazolamide and the ventilatory response to hypoxia: comparison of eucapnic and hypercapnic conditions [abstract]. Am Rev Respir Dis 1980;121(suppl):392.

29 Coudon WL, Block AJ. Acute respiratory failure precipitated by a carbonic anhydrase inhibitor. Chest 1976;69:112-3.

30 Heller I, Halevy J, Cohen S, Theodor E. Significant metabolic acidosis induced by acetazolamide not a rare complication. Arch Intern Med 1985;145:1815-7. 